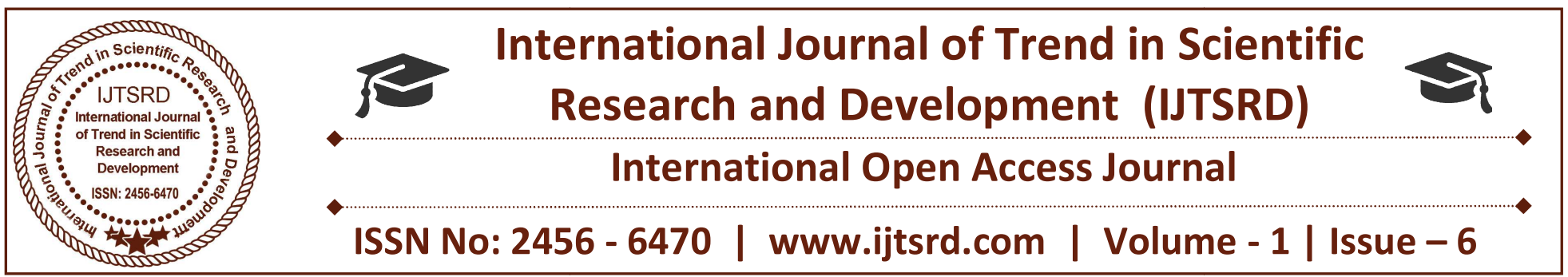

\title{
Targeted Intermediates of Eudesmic Acid: Synthesis and X-ray Investigations
}

Olimova M.I.

Organic Synthesis Department,

Sobir Yunusov Institute of Chemistry of the Plant Substances,

Academy of Sciences of the

Republic of Uzbekistan,

Tashkent, Uzbekistan

\author{
Okmanov R. Ya. \\ Organic Synthesis Department, \\ Sobir Yunusov Institute of \\ Chemistry of the Plant Substances, \\ Academy of Sciences of the \\ Republic of Uzbekistan, \\ Tashkent, Uzbekistan
}

\author{
Elmuradov B. Zh. \\ Organic Synthesis Department, \\ Sobir Yunusov Institute of \\ Chemistry of the Plant Substances, \\ Academy of Sciences of the \\ Republic of Uzbekistan, \\ Tashkent, Uzbekistan
}

\section{ABSTRACT}

It was carried out synthesis of esters and their dinitro derivatives of 3,4,5-trimethoxybenzoic (eudesmic) acid. Esterification of eudesmic acid carried out $n$ absolute methanol or ethanol and corresponding methyl and ethyl 3,4,5-trimethoxybenzoates (2, 3) have been synthesized in good yields. It was revealed that nitration of these esters gives only dinitro products. The structure of the synthesized compounds of the methyl and ethyl 2,6-dinitro-3,4,5trimethoxybenzoates $(4,5)$ was determined by X-ray diffraction analysis (XRD). In the asymmetric part of the crystal structures of 4,5 one and two molecules are observed, respectively. In crystalline structures a flat nitro groups and carboxylic groups do not participate in the conjugation with aromatic rings. In the crystal structure of 4, an intermolecular $\mathrm{C} 8-\mathrm{H}$...O9 hydrogen bond is observed, these $\mathrm{H}$ bonds link the molecules along the [010] axis. In the crystal structure of 5, intermolecular C9B-H...O4A and C10B-H...O8A hydrogen bonds form chains along the [011] axis. The formed chains are cross linked by the intermolecular C9B-H...O5A hydrogen bonds.

Keywords: synthesis; methyl and ethyl 3,4,5trimethoxybenzoates; methyl and ethyl 2,6-dinitro3,4,5-trimethoxybenzoates; esterification; nitration; $X$ ray diffraction analysis

\section{INTRODUCTION}

Eudesmic acid is an O-methylated trihydroxybenzoic (gallic) acid (1). This natural carboxylic acid can be found in Eucalyptus spp. [1].

There is in medicine practice more than 20 drugs are successfully used, such as: trimebutine with antimuscarinic effect [2] and its maleic acid saltrecutin, polybutin [3], trimetozine (sedative activity) $[4,5]$ is used in Europe since 1959 and has been used in the treatment of anxiety [6,7], dilazep (vasodilator) acts as an adenosine reuptake inhibition [8], troxipide is a drug used in the treatment of gastroesophageal reflux disease and it is novel systematic nonantisecretory gastric cytoprotective agent with antiulser, anti-inflammatory properties [9-14], methoserpidine [15] is an antihypertensive drug related to reserpine and its analogues [16] some 3,4,5trimethoxybenzoic acid derivatives have been synthesized and studied their activity on the central nervous system [17]. Discussion of literatures shows that 3,4,5-trimethoxybenzoic acid and its derivatives are very interest and important synthons for creation of pharmacologically active drugs.

Aim of this work is developing effective methods for synthesis of 2,6-dinitro-3,4,5-trimethoxybenzoic acid, which has reactive carboxylic group and studying their 
X-ray structure. We can successfully use this synthones in the synthesis of many potential bioactive substances and for introduction of pharmacophoric fragments of eudesmic acid into molecules of different natural [18] and synthetic heterocyclic compounds [19]. These investigations will be presented in our next publications.

\section{MATERIALS AND METHODS}

${ }^{1} \mathrm{H}$ NMR spectrum was recorded in acetone- $d_{6}$ on Varian 400-MR spectrometer operating accordingly at $400 \mathrm{MHz}$. Hexamethyldisiloxcane (HMDSO) was used as internal standard, chemical shift $\delta$ of ${ }^{1} \mathrm{H}$ was recorded in ppm. Mps were measured on a Boetius and MEL-TEMP apparatus manufactured by Barnstead International (USA) and were uncorrected. IR spectra were recorded on IR Fury System 2000 (Perkin-Elmer) as $\mathrm{KBr}$ pellets.

The reactionary process was monitored by TLC on Whatman UV-254 precoated aluminum plates using $\mathrm{CHCl}_{3} / \mathrm{CH}_{3} \mathrm{OH}-10: 1, \mathrm{C}_{6} \mathrm{H}_{6} / \mathrm{CH}_{3} \mathrm{OH}-25: 1$ solvent system and developed plates were visualized under UV lamp and/or iodine tank where necessary. Solvents were purified by standard procedures. Organic solutions were dried over anhydrous $\mathrm{Na}_{2} \mathrm{SO}_{4}$ and concentrated with a RVO-64 ROT VAC Evaporator at reduced pressure.

\section{X-ray diffraction studies of compounds 4 and 5.}

The crystals of compounds $\mathbf{4}$ and $\mathbf{5}$, suitable for X-ray diffraction, were grown by slow evaporation of solvent - EtOH at room temperature. The crystal cell parameters are determined and refined on a CCD Xcalibur Ruby (Oxford Diffraction) diffractometer using $\mathrm{CuK} \square$-radiation. The correction for absorption was introduced by the Multi-scan method.

A CrysAlis Pro program package was used for the determination of cell parameters, data integration, scaling and absorption correction [21]. The structures were solved by direct methods (SHELXS-97) [22] and refined by full matrix least-square procedures on $F^{2}$ (SHELXL-97) [23]. The non-hydrogen atoms were refined anisotropically and hydrogen atoms were placed at idealized positions and refined using the riding model. A summary of the fundamental crystal and refinement data is provided in Table 2 . Crystallographic data for the structural analysis was deposited with the Cambridge Crystallographic Data
Centre. A copy of this information may be obtained free of charge from: The Director, CCDC, 12 Union Road, Cambridge, CB2 1EZ, UK. Fax: +44 1223336 033, e-mail:deposit@ccdc.cam.ac.uk, or www.ccdc.cam.ac.uk.

Table 2 General crystallographic parametrs and charasteristics of X-ray analysis of the compounds 4 and $\mathbf{5}$

\begin{tabular}{|c|c|c|}
\hline Compounds & 4 & 5 \\
\hline Formula & $\mathrm{C}_{11} \mathrm{H}_{12} \mathrm{~N}_{2} \mathrm{O}_{9}$ & $\mathrm{C}_{12} \mathrm{H}_{14} \mathrm{~N}_{2} \mathrm{O}_{9}$ \\
\hline Formula weight & 316,23 & 330,25 \\
\hline Crystal system & orthorhombic & triclinic \\
\hline Space group & Pbca & $P-1$ \\
\hline $\mathrm{Z}$ & 8 & 4 \\
\hline $\mathrm{T}(\mathrm{K})$ & $290(2)$ & $290(2)$ \\
\hline $\mathrm{a}(\AA)$ & $17,998(4)$ & $8,5444(17)$ \\
\hline $\mathrm{b}(\AA)$ & $8,3932(17)$ & $9,895(2)$ \\
\hline c $(\AA)$ & $19,012(4)$ & $18,785(4)$ \\
\hline$\alpha\left(^{\circ}\right)$ & 90,0 & $90,93(3)$ \\
\hline$\beta\left(\left(^{\circ}\right)\right.$ & 90,0 & $91,75(3)$ \\
\hline$\gamma\left({ }^{\circ}\right)$ & 90,0 & $105,41(3)$ \\
\hline $\mathrm{V}\left(\AA^{3}\right)$ & $2872,1(10)$ & $1529,9(5)$ \\
\hline $\mathrm{Dx}\left(\mathrm{g} \mathrm{cm}^{-3}\right)$ & 1,463 & 1,434 \\
\hline $\mathrm{F}(000)$ & 1312 & 688 \\
\hline$\mu\left(\mathrm{mm}^{-1}\right)$ & 1,136 & 1,090 \\
\hline$\Theta$ range $\left(^{\circ}\right)$ & $4,65-76,09$ & $4,64-76,02$ \\
\hline hkl range & $\begin{array}{l}-15 \leq \mathrm{h} \leq 22 \\
-8 \leq \mathrm{k} \leq 10 \\
-23 \leq 1 \leq 20\end{array}$ & $\begin{array}{l}-10 \leq \mathrm{h} \leq 7 \\
-11 \leq \mathrm{k} \leq 11 \\
-23 \leq 1 \leq 20\end{array}$ \\
\hline $\begin{array}{l}\text { Measured } \\
\text { reflections }\end{array}$ & 7170 & 10478 \\
\hline $\begin{array}{l}\text { Independent } \\
\text { reflections }\end{array}$ & 2923 & 6151 \\
\hline $\begin{array}{l}\text { Reflections with } I \\
>4 \sigma(I)\end{array}$ & 1572 & 3564 \\
\hline $\mathrm{R}\left[F^{2}>4 \sigma\left(F^{2}\right)\right] /$ all & 0,0586 & 0,0604 \\
\hline $\mathrm{wR}\left(F^{2}\right)$ & 0,1390 & 0,1605 \\
\hline S all & 0,995 & 0,991 \\
\hline Parameters & 204 & 424 \\
\hline $\operatorname{Max} / \min \Delta \rho\left(\mathrm{e} \AA^{-3}\right)$ & $0,174 /-0,213$ & $0,293 /-0,275$ \\
\hline CCDC & 1546900 & 1546901 \\
\hline
\end{tabular}

\section{Synthesis of esters $(2,3)$}

Methyl 3,4,5-trimethoxybenzoate (2). 9.5 g (45 mmol) 3,4,5-trimethoxybenzoic acid was dissolved in $140 \mathrm{ml}$ absolute methanol, $4.75 \mathrm{ml}$ concentrated $\mathrm{H}_{2} \mathrm{SO}_{4}$ was added. Reaction mixture was refluxed for 8 
$\mathrm{h}$, filtered hot, and is cooled up to $5-10^{\circ} \mathrm{C}$. The formed crystals were filtered off and dried.

Yield: $8.64 \mathrm{~g}(85 \%), \mathrm{mp} 82-83^{\circ} \mathrm{C}$ (abs. methanol), $\mathrm{R}_{\mathrm{f}}$ $0.4\left(\mathrm{CHCl}_{3} / \mathrm{CH}_{3} \mathrm{OH}-10 / 1\right)$.

Ethyl 3,4,5-trimethoxybenzoate (3). Reaction carried out analogously: $10 \mathrm{~g} \quad(47 \mathrm{mmol}) \quad 3,4,5-$ trimethoxybenzoic acid was dissolved in $150 \mathrm{ml}$ absolute ethanol, $10 \mathrm{ml}$ concentrated $\mathrm{H}_{2} \mathrm{SO}_{4}$ was added. Reaction mixture was refluxed for $8 \mathrm{~h}$, filtered hot, and is cooled up to $5-10^{\circ} \mathrm{C}$. The formed crystals filtered off and dried.

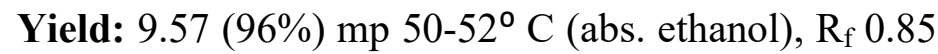
$\left(\mathrm{CHCl}_{3} \backslash \mathrm{CH}_{3} \mathrm{OH}-10 / 1\right)$

\section{Synthesis of dinitroproducts $(4,5)$}

Methyl 2,6-dinitro-3,4,5-trimethoxybenzoate (4) $1.93 \mathrm{~g}$ (8.5 mmol) methyl 3,4,5-trimethoxybenzoate (2) was dissolved in cooled $4 \mathrm{ml}$ concentrated $\mathrm{H}_{2} \mathrm{SO}_{4}$ (ice bath, $30 \mathrm{~min}$.) and nitrating mixture, containing $2.9 \mathrm{~g} \mathrm{HNO}_{3}$ and $2.7 \mathrm{~g} \mathrm{H}_{2} \mathrm{SO}_{4}$ acids were added drop wise for $1 \mathrm{~h}$, mixed for $30 \mathrm{~min}$ in ice bath and for $1 \mathrm{~h}$ at room temperature. Reaction mixture was decomposed with crushed ice. The formed yellow crystals were filtered off and washed with water up to $\mathrm{pH}=7$ and dried.

Yield: $0.68(50 \%), \mathrm{mp} 106-108^{\circ} \mathrm{C}$ (methanol), $\mathrm{R}_{\mathrm{f}} 0.4$ $\left(\mathrm{C}_{6} \mathrm{H}_{6} / \mathrm{CH}_{3} \mathrm{OH}-25 / 1\right)$

${ }^{1} \mathrm{H}$ NMR spectrum (acetone- $d_{6}$ ), $\delta, \mathrm{ppm}, \mathrm{J} / \mathrm{Hz}: 4.07$ (3H, s, COOMe), 4.03 (6H, s, OMe-3,5), 3.78 (3H, s, OMe-4).

IR $(\mathrm{KBr}) \mathrm{cm}^{-1}: 2961\left(\mathrm{CH}_{3}\right), 1738(\mathrm{O}-\mathrm{C}=\mathrm{O}), 1574$, $1545\left(\mathrm{NO}_{2}\right)$.

\section{Ethyl 2,6-dinitro-3,4,5-trimethoxybenzoate (5).}

Reaction carried out analogously to the synthesis method of compound 4 .

From $6 \mathrm{~g}$ (25 mmol) of ethyl 3,4,5-trimethoxybenzoate (3) in $14 \mathrm{ml}$ concentrated $\mathrm{H}_{2} \mathrm{SO}_{4}$ (ice bath) and nitrating mixture $\left(8.96 \mathrm{~g} \mathrm{HNO}_{3}+8.47 \mathrm{H}_{2} \mathrm{SO}_{4}\right)$ the corresponding compound $\mathbf{5}$ has been synthesized.

Yield: $2.0 \mathrm{~g}(48 \%), \mathrm{mp} 70-72^{\circ} \mathrm{C}$ (ethanol), $\mathrm{R}_{\mathrm{f}} 0.8$ $\left(\mathrm{C}_{6} \mathrm{H}_{6} / \mathrm{CH}_{3} \mathrm{OH}-25 / 1\right)$

${ }^{1} \mathrm{H}$ NMR spectrum (acetone- $\left.d_{6}\right), \delta, \mathrm{ppm}, \mathrm{J} / \mathrm{Hz}: 4.1(2 \mathrm{H}$, q, $\left.\mathrm{OCH}_{2}\right), 4.0\left(3 \mathrm{H}, \mathrm{t}, \mathrm{OCH}_{2} \underline{\mathrm{CH}}_{3}\right), 3.9(6 \mathrm{H}, \mathrm{s}, \mathrm{OMe}-$ 3,5), 3.7 (3H, s, OMe-4).

IR $(\mathrm{KBr}) \mathrm{cm}^{-1}: 2957\left(\mathrm{CH}_{3}\right), 1734(\mathrm{O}-\mathrm{C}=\mathrm{O}), 1570$, $1542\left(\mathrm{NO}_{2}\right)$.

\section{RESULTS AND DISCUSSION}

Continuing researches on the synthesis of perspective derivatives of 3,4,5-trimethoxybenzoic acid, in this work we carried out esterification of 3,4,5trimethoxybenzoic acid and nitration of obtained methyl and ethyl 3,4,5-trimethoxybenzoates $(2,3)$.

Esterification of 3,4,5-trimethoxybenzoic acid (1) was carried out in absolute methanol and ethanol in the presence of concentrated sulfuric acid in reflux for $8 \mathrm{~h}$ :

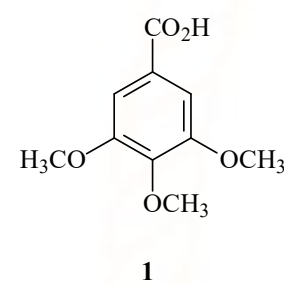

The synthesized esters $(\mathbf{2}, \mathbf{3})$ can react with nitrating mixture (mixture of nitric and sulfuric acids) at $-2-0{ }^{\circ} \mathrm{C}$ (ice bath) for 1.5-2 $\mathrm{h}$ and methyl and ethyl 2,6-dinitro3,4,5-trimethoxybenzoates $(\mathbf{4}, \mathbf{5})$ in moderate yields:
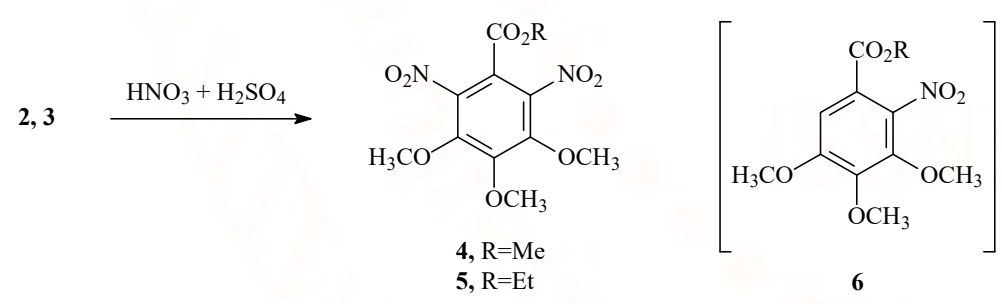

No formation of mono-nitro product - methyl and ethyl 2-nitro-3,4,5-trimethoxybenzoates was (6) observed. Formation of mono-nitro product (6) takes place at the nitration of compound 4 by nitric acid in the medium of acetic acid [20].

Structures of synthesized methyl and ethyl 2,6-dinitro3,4,5-trimethoxybenzoates $(\mathbf{4}, \mathbf{5})$ have been confirmed by physical research, including methods for the analysis of X-ray diffraction of single crystals. The XRD analysis of compound 4 shows that in an independent part of the crystal structure contains one molecule of methyl 2,6-dinitro-3,4,5- 
International Journal of Trend in Scientific Research and Development (IJTSRD) ISSN: 2456-6470

trimethoxybenzoate. Aromatic ring is flat (C1-C6) [r.m.s. deviation $0.0135 \AA$, the angles between the aromatic ring and the flat carboxyl group $(\mathrm{C} 7 / \mathrm{O} 1 / \mathrm{O} 2)$ are $35.69(11)^{\circ}$. Angles between the aromatic ring and nitro groups also are $64.06(16)^{\circ}(\mathrm{N} 2 / 08 / 09),-75.67$ $(15)^{\mathrm{o}}(\mathrm{N} 1 / \mathrm{O} 3 / \mathrm{O} 4)$ (Table 1). This arrangement of carboxyl $(\mathrm{C} 1)$ and two nitro groups $(\mathrm{C} 2, \mathrm{C} 6)$ gives evidence that these planar fragments do not participate in the conjugation of the p-electrons of the aromatic ring. A similar picture in the arrangement of nitro groups is observed in the structure of the molecule methyl 2-nitro-3,4,5-trimethoxybenzoate [20]. In the crystal of the compound $\mathbf{4}$ is observed a weak intermolecular C8-H...O9 hydrogen bond. Parameters:

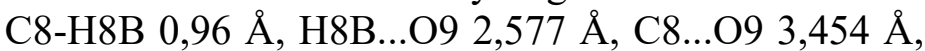

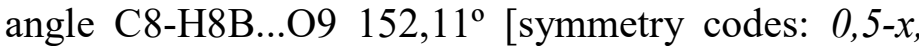
$0,5+y,+z]$, These H-bonds bind the molecules along the $[010]$ axis.

The XRD results of the compound $\mathbf{5}$ show that in the independent part of the crystal structure there are two ethyl 2,6-dinitro-3,4,5-trimethoxybenzoate (5A and 5B) molecules. The arrangement of flat fragments of carboxyl groups and nitro groups is different and they do not participate in conjugation of the p-electrons of the aromatic ring. The aromatic ring $(\mathbf{5 A})$ is flat $(\mathrm{C} 1-$ C6) [r.m.s. deviation $0.0101 \AA$ ], the angle between the carboxyl group $(\mathrm{C} 7 / \mathrm{O} 1 / \mathrm{O} 2)$ is $10.32(7)^{\circ}$, the angles between the nitro groups are $83.85(15)^{\circ}$ (N2/O8/O9), $84.37(18)^{\circ}(\mathrm{N} 1 / \mathrm{O} 3 / \mathrm{O} 4)$. The aromatic ring (5B) is flat (C1-C6) [r.m.s. deviation $0.0129 \AA$ ], the angle between the carboxyl group $(\mathrm{C} 7 / \mathrm{O} 1 / \mathrm{O} 2)$ is 45.79 $(17)^{\circ}$, the angles between nitro groups are $-65.55(17)^{\circ}$ (N2/O8/O9), $61.53(15)^{\circ}(\mathrm{N} 1 / \mathrm{O} 3 / \mathrm{O} 4)$ (Table 1). In the crystal structure of $\mathbf{5}$, the formation of weak intermolecular C9B-H...O4A and C10B-H...O8A hydrogen bonds, forming the chain along the [011] axis is observed. The formed chains are cross linked by the intermolecular C9B-H...O5A hydrogen bonds.

Parameters of C9B-H9BA...O4A hydrogen bonds: distance C9B-H9BA 0,96 $\AA$, H9BA...O4A 2,688 $\AA$, C9B...O4A 3,582 $\AA$, angle C9B-H9BA...O4A 155,17 [symmetry codes: $-x,-y-1,-z$ ]; C10B-H10F...O8A: distance C10B-H10F $0.96 \AA$, H10F...O8A 2,612 $\AA$, C10B...O8A 3,501 $\AA$, angle C10B-H10F...O8A $154,04^{\circ}$ [symmetry codes: $\left.-x,-y,-z+1\right]$; C9BH9BB...O5A: distance C9B-H9BB $0.96 \AA$, H9BB...O5A $2.593 \AA$, C9B...O5A $3.538 \AA$, angle C9B-H9BA...O5A $168.08^{\circ}$. The structures of the methyl and ethyl 2,6-dinitro-3,4,5trimethoxybenzoates $(\mathbf{4}, \mathbf{5})$ are shown in Fig. 1.
Table 1: Torsion angles $\left(^{\circ}\right)$ of 4 and 5 fragments

\begin{tabular}{|l|l|l|l|}
\hline $\begin{array}{l}\text { Torsion } \\
\text { angles }\left(^{\circ}\right)\end{array}$ & 4 & $5 A$ \\
\hline O3-N1-C2-C1 & $\begin{array}{l}74,66 \\
(42)\end{array}$ & $-95,95(40)$ & $118,79(34)$ \\
\hline O4-N1-C2-C1 & $\begin{array}{l}-105,22 \\
(37)\end{array}$ & $84,58(42)$ & $-59,81(41)$ \\
\hline O3-N1-C2-C3 & $\begin{array}{l}-102,35 \\
(37)\end{array}$ & $83,19(41)$ & $-64,65(40)$ \\
\hline O4-N1-C2-C3 & $\begin{array}{l}77,77 \\
(40)\end{array}$ & $-96,28(39)$ & $116,76(34)$ \\
\hline O9-N2-C6-C5 & $\begin{array}{l}-113,80 \\
(36)\end{array}$ & $-94,09(35)$ & $112,47(34)$ \\
\hline O8-N2-C6-C5 & $\begin{array}{l}65,11 \\
(43)\end{array}$ & $83,73(37)$ & $-66,21(41)$ \\
\hline O9-N2-C6-C1 & $\begin{array}{l}62,01 \\
(46)\end{array}$ & $84,22(38)$ & $-63,94(41)$ \\
\hline O8-N2-C6-C1 & $\begin{array}{l}-119,09 \\
(38)\end{array}$ & $-97,96(36)$ & $117,38(35)$ \\
\hline C2-C1-C7-O2 & $\begin{array}{l}-141,49 \\
(36)\end{array}$ & $\begin{array}{l}-169,99 \\
(33)\end{array}$ & $-44,51(44)$ \\
\hline C6-C1-C7-O2 & $\begin{array}{l}33,87 \\
(52)\end{array}$ & $10,24(50)$ & $131,92(34)$ \\
\hline C2-C1-C7-O1 & $\begin{array}{l}36,66 \\
(43)\end{array}$ & $10,68(46)$ & $137,43(29)$ \\
\hline C6-C1-C7-O1 & $\begin{array}{l}-147,98 \\
(31)\end{array}$ & $\begin{array}{l}-169,10 \\
(30)\end{array}$ & $-46,14(39)$ \\
\hline
\end{tabular}




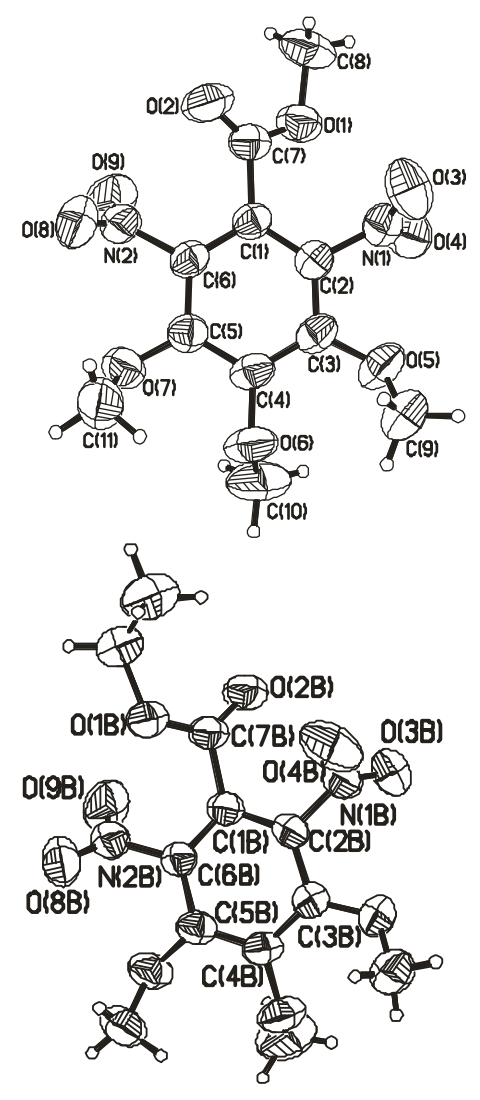

Figure 1 A representation of the molecular structure of 4 and 5 with atom labeling scheme. Ellipsoids correspond to $50 \%$ probability level.

\section{CONCLUSIONS}

It was carried out synthesis of dinitro derivatives of 3,4,5-trimethoxybenzoic (eudesmic) acid - methyl and ethyl 2,6-dinitro-3,4,5-trimethoxybenzoates (4, 5), which are important synthones in the organic and bioorganic chemistry. It was found that nitration of methyl and ethyl 3,4,5-trimethoxybenzoates $(2,3)$ by nitrating mixture corresponding dinitro products methyl and ethyl 2,6-dinitro-3,4,5trimethoxybenzoates $(4,5)$ are synthesized and their structures were determined by X-ray diffraction analysis (XRD). No formation of mono-nitro product was (6) observed. It was revealed that in the asymmetric part of the crystal structures of 4, 5 one and two molecules are observed. It was observed that in the crystalline structures a flat nitro groups and carboxylic groups do not participate in the conjugation with aromatic rings, and in the crystal structures of $\mathbf{4}$ and $\mathbf{5}$ an intermolecular hydrogen bond are observed, which these $\mathrm{H}$ bonds link the molecules along the [010] and [011] axis, respectively.

\section{ACKNOWLEDGEMENT}

We thank the Academy of Sciences of the Republic of Uzbekistan for supporting this study (Grant VA-FA-F7-006: "Fundamentals of synthesis of the selective pesticides of new generation in the series of sulfonylurea, triazines and their heterocyclic analogues $\left.{ }^{6}\right)$.

\section{REFERENCES}

1) HPLC analysis of flavonoids and phenolic acids and aldehydes in Eucalyptus spp. E. Conde, E. Cadahía and M. C. Garcia-Vallejo, Chromatographia, Volume 41, Numbers 11-12, 657-660, doi:10.1007/BF02267800

H. Kaneto, M. Takahashi and J. Watanabe, The opioid receptor selectivity for trimebutine in isolated tissues experiments and receptor binding studies. Journal of Pharmacobiodynamics. 1990, 13(7): 448-453.

3) Ok Hwa Jhee, Yun Sik Lee, Leslie M. Shaw, Yong Cheol Jeon, Min Ho Lee, Seung Hoon Lee, Ju Seop Kang. The pharmacokinetic and bioequivalence evaluation of two formulations of $100 \mathrm{mg}$ trimebutine maleate (Recutin and Polybutin) in healthy male volunteers using the LC-MS/MS method. Clinica Chimica Acta. 2007, 375 (1-2): 69-75.

4) [4] Swiss Pharmaceutical Society (2000). Index Nominum 2000: International Drug Directory. Boca Raton: Medpharm Scientific Publishers. p.1932.

5) David J. Triggle (1997). Dictionary of pharmacological agents. London: Chapman \& Hall.

6) P. Taverna and G. Ferrari (June 1970). "Clinical trial of a new tranquilizing agent: trioxazine". Minerva Medica (in Italian). 61 (46): 2574-90.

7) V.M. Shpak and A. Shcheglova (August 1968). "Trioxazine in the treatment of night anxiety in children". Pediatriia (in Russian). 47 (8): 76-7.

8) Hiroshi Deguchi, Hiroyuki Takeya, Hideo Wada, Esteban C. Gabazza, Nobuyuki Hayashi, Hajime Urano, Koji Suzuki. Dilazep, an Antiplatelet agent, inhibits tissue factor expression in endothelial Cells and Monocytes. Blood., 1997, 90: 23452356.

9) Y. Abe, H. Sekiguchi, K. Tsuru and T. Irikura (1984). "Effects of 3,4,5-trimethoxy-N-(3piperidyl) benzamide (KU-54) on the incorporation (excretion) of ${ }^{14} \mathrm{C}$-glucosamine in the gastric 
mucosa and the liver of rats (Article in Japanese)". Nihon Yakurigaku Zasshi. 84 (1): 11-8.

10) T. Mine, A. Kataoka and J. Fujisaki, "Effects of cimetidine and troxipide on gastric mucosal prostaglandin synthesis in patients with chronic gastric ulcer". Curr Ther Res. 50 (6): 878-87.

11) T. Yoshikawa, Y. Naito (2000). "The role of neutrophils and inflammation in gastric mucosal injury". Free Radic Res. 33 (6): 785-94. doi:10.1080/10715760000301301.

12) K. Kusugami, K. Ina, T. Hosokawa, F. Kobayashi, H. Kusajima, K. Momo, Y. Nishio (May 2000). "Troxipide, a novel antiulcer compound, has inhibitory effects on human neutrophil migration and activation induced by various stimulants". Dig Liver Dis. 32 (4): 305-11. doi:10.1016/S15908658(00)80023-7.

13) Hyeoyun (1989). "Peptic ulcers for the clinical effectiveness of Troxipide". Latest Med. 32 (2): 125-31.

14) B. Dewan and A. Balasubramanian (2010). "Troxipide in the management of gastritis: a randomized comparative trial in general practice". Gastroenterol Res Pract. 2010: 758397. doi:10.1155/2010/758397.

15) D.L. Jones, A.M. Michael and J.P. Ommer (1961), "Clinical Trial of Methoserpidine in General Practice". British Medical Journal. 2 (5269): 17381741. doi:10.1136/bmj.2.5269.1738.

16) M.A. Karim, W.H. Linnel and L.K. Sharp, Potential reserpine analogues. Part II. 3,4,5-
Trimethoxybenzoic acid derivatives. J. Pharm. Pharmacol., 1960, 12: 82-86.

17) R. Glinka, H. Mikolajewska, A. Szadowska and M. Kielek, Synthesis and the study of the effect of new 3,4,5-trimethoxybenzoic acid derivatives on the central nervous system. Acta Pol. Pharm., 1985, 42(2): 117-122.

18) Kh.M. Shakhidoyatov and B.Zh. Elmuradov Tricyclic quinazoline alkaloids: isolation, synthesis, chemical modification and biological activity. Chem. Nat. Compd., 2014, 50 (5): 781800.

19) B.Zh Elmuradov, K.M. Shakhidoyatov, G. Dräger and H. Butenschön, Tricyclic quinazoline alkaloids conjugated to ferrocene. Synthesis, structure, and redox behavior of ferrocenylmethylene substituted 7Hdeoxyvasicinones. Eur. JOC, 2016, 483-492.

20) Jean Fotie, Alan Olvera, Suraj K. Ayer, Honore Djieutedjeu, Pierre F. P. Poudeu. Synthesis and crystal structures of methyl 3,4,5trimethoxybenzoate and 1,2-dihydro-2,2,4trimethylquinoline derivatives. J. Chem. Crystallogr., 2015, 45:1-8.

21) Agilent (2014) CrysAlis PRO (version 1.171.37.34). Agilent Technologies Ltd., Yarnton, England.

22) G. M. Sheldrick (2008). Acta Cryst. A64, 112-122. 23) G. M. Sheldrick (2015). Acta Cryst. C71, 3-8. 